[Aus der 'bakteriologisch-serologischen Abteilung des Städt'. Krankenhauses Altona/Élbe.

(Oberarzt Dr. Johannes Zeisaler.)]

\title{
Die Diagnose des Meningococcus Weichselbaum und ihre Vereinheitlichung.
}

Vorschläge auf Grund eigener Erfahrung und einer kritischen Literaturstudie der während des Krieges erschienenen Meningokokkenarbeiten.

Von

Dr. Johannes Zeissler und Prof. Dr. Gustav Gassner.

Die besonderen Verhältnisse des Krieges haben an verschiedenen Stellen zu einer Häufung genickstarreartiger Erkrankungen geführt und sind so die Ursache einer größeren Anzahl von Untersuchungen und Veröffentlichungen, die sich teils mit klinischen und anatomischen Einzelheiten der Meningitis, teils mit dem bakteriologischen und serologischen Nachweis und der Identifizierung des Krankheitserregers befassen.

Wenn wir die während des Krieges erschienenen, die bakteriologische Diagnose des Weichselbaumschen Meningococcus behandelnden Arbeiten überblicken, so ergeben sich außerordentliche Verschiedenheiten und vielfach beträchtliche, biswoilen sogar bedenkliche Unsicherheiten. Die einzelnen für die Diagnose in Betracht kommenden Merkmale werden von den versehiedenen Autoren sehr ungleich bewertet und folglich in sehr ungleichem Maße zur Diagnose herangezogen. Dementsprechend sind die von den einzelnen Autoren gewonnenen Ergebnisse und die daraus von ihnen gezogenen Schlußfolgerungen sehr ungleichwertig und dürfen daher z. B. hinsichtlich des gefundenen Prozentsatzes an Keimträgern nicht in unmittelbaren Vergleich gesetzt werden.

Im Hinblick auf das Vorstehende ist es bedauerlich, daß eine Reihe von Untersuchern über die Einzelheiten der von ihnen angewandten Methodik keinerlei Angaben bringen: Bittorf (4), Brach und Fröhlich (6), 
Küster (51), so daß eine Bewertung der Ergebnisse dieser Arbeiten sehr erschwert wird.

In der Mehrzahl der Arbeiten werden zwar Angaben über Einzelheiten der bakteriologisehen Diagnostik gebracht, aber gerade diese Angaben verunlassen uns, hier ausführlich auf die Frage der Meningokokkendiagnose einzugehen.

In mehreren Fällen wird die Diagnose ausschließlich auf Grund einfacher mikroskopischer Untersuchung gestellt. Sanitätsrat Herzog (38) und Börnstein (5) bezeichnen selbst deshalb ihre Diagnose als unzureichend, während Wolff (82) Mühsam (58), Hryntschak (41) und Kudruáč (49) keine derartige Selbstkritjk üben. Auch die an sich guten Anreicherungsmethoden von Ernst Fraenkel (17) und von Obé (59) sind von ihren Autoren nur für die Erleichterung des direkten mikroskopischen Nachweises geschaffen. Noch bedenklicher ist natürlich der ausschließlich mikroskopische Nachweis der Meningokokken in den Fällen, in welchen nicht die vorschriftsmäßige Gramfärbung angewendet, sondern wie von Goebel und Hess (28) eine einfache Methylenblaufärbung als ausreichend erklärt wird. Bei Morgenstern (57) und Rosenbaum (64) fehlen Angaben über die Art der angewandten Färbung.

Auf vorschriftsmäBige Durchführung der Gramfärbung muß, wie Zeissler (84) unlängst betonte, besonderer Wert gelegt werden; es gilt das selbstverständlich auch für diejenigen Fälle, in denen die mikroskopische Untersuchung nicht allein zur Diagnose herangezogen wird, sondern neben dem kulturellen Nachweis zur Anwendung kommt. Es muß darauf bestanden werden, daB mit Anilinwasser-Gentianaviolett nach der Gram schen Originalvorschrift (31) gearbeitet wird; es ist unzulässig, Methylviolett zu nehmen, auch darf nur mit absolutem Alkohol und ohne vorheriges Abspülen mit Wasser entfärbt werden. So selbstverständlich dies alles klingt, wird es doch noch immer nicht genügend beachtet, und das führt dann, wie z. B. aus den Mitteilungen von Köhlisch (48) hervorgeht, zur Entdeckung atypischen und unsicheren Gramverhaltens der Kokken.

Gramfärbung und mikroskopische Untersuchung geben ein außerordentlich wertvolles Hilfsmittel für die Meningokokkendiagnose ab, da auch das mikroskopische Bild: ungleiche KorngröBe der Kokken, unregelmäßige Tingierbarkeit, Tetradenlagerung [die Angabe von Schwenke (70) über Kapselbildung verdient keine Berïcksichtigung] sehr charakteristisch ist, schließen jedoch Verwechslungen der Meningokokken mit naheverwandten Keimen nicht aus. Daher begnügen sich in der weitaus überwiegenden Mehrzahl der Arbeiten die Autoren nicht mit dem rein mikroskopischen Nachweis des Krankheitserregers, sondern gehen zum kulturellen 
Nachweis über, allerdings ohne immer die nötigen Angaben beizufügen, in welcher Weise dieser kulturelle Nachweis durchgeführt ist:-Bit torf $(3,4)$, Brach und Fröhlich (6), Götz und Hanfland (30), Gruber (33), Küster (51), v. Kutschera (53), Pick (62), Rosenbaum (64). Dieses Fehlen näherer Angaben kann als Mangel empfunden werden, denn wie die folgenden Ausführungen lehren, sind die angewendeten Untersuchungsmethoden zu ungleichwertig, um ohne Kenntnis der Einzelheiten ein Urteil über die Richtigkeit der auf sie begründeten Diagnosen zu gestatten. Solange wir noch nicht eine allgemein anerkannte diagnostische Technik des Meningokokkennachweises, etwa nach Art des Cholera- oder Typhusnachweises, besitzen, muß die Forderung erhoben werden, als Grundlage jeder Arbeit über Meningokokken die Einzelheiten des jeweils gebrauchten kulturellen Verfahrens mit genügender Deutlichkeit wiederzugeben. Dieser Forderung ist auch in den im folgenden erwähnten Arbeiten, welche überhaupt Angaben über die Art des durchgeführten kulturellen Nachweises bringen, nicht immer voll nachgekommen.

Das Herausz üchten der Meningokokken, sei es aus Rachenabstrichen, sei es aus Lumbalpunktaten, erfolgt im allgemeinen mittels As zitesagars: Börnstein (5), Gassner (21), Ghon (25), Hancken (35), Harzer und Lange (36), G. Herzog (37), Imhofer (43), Isaak (44), Jochmann (45), Justitz (46), Klinger und Fourman (47), Küster und Günzler (52), Silbergleit und Angerer (71), Svestka (76), Zeissler und Riedel (84). Das Wachstum auf Aszitesagar wird gleichzeitig noch zu differentialdiagnostischen Zwecken herangezogen.

Gewöhnlicher Agar oder Glyzerinagar ohne Aszites- oder Menschenserumzusatz findet nur als differentialdiagnostisches Hilfsmittel Verwendung: Gassner (21), Hancken (35), Harzer und Lange (36), Imhofer (43), Jochmann (45), Klinger und Fourman (47), Küster und Günzler (52), Stephan (74), Zeissler und Riedel (84).

Kultur auf Loefflerserum wird von Börnstein (5), Ghon (25) und Jochmann (45) angewendet und von Hancken (35) als besonders wertvoll zur Unterscheidung der Meningokokken von verwandten Keimen empfohlen.

Als wichtigste differentialdiagnostische Nährböden gelten vielen Autoren die Lingelsheimschen Zuckernährböden. Aber gerade über deren Zuverlässigkeit gehen die Berichte der verschiedenen Untersucher weit auseinander (Darré und Dumas (10), Fromme und Hancken (19), Gassner (21), Hancken (35), Harzer und Lange (36), Isaak (44), Klinger und Fourman (47), Schwenke (70), Zeissler und Riedel (84).

Der seinerzeit von Schottmüller (69) empfohiene Menschenblut- 
agar findet sich, abgesehen von Versuchen zur Züchtung der Keime aus dem strömenden Blut: v. Angerer (1), Bittorf (3), Bray (7), Schwenke (70), Zeissler und Riedel(84), soweit hierfür nicht Bouillonkulturen verwendet sind, selten erwähnt: Eugen Fränkel (18), Gassner (21), Jochmann (45), Zeissler und Riedel (84).

Von vereinzelt angewendeten Spezialnährböden wie Rinderserumagar [Klinger und Fourman(47)], Pferdeserumagar [Gassner(21)], Ochsenherzfleisch-Blutagar [Lloyd (55)], Eiereiweißagar [Sacquépée und Delater (66)] wird weiter unten noch die Rede sein, ebenso von der Verwendung von Gelatinenährböden [Harzer und Lange (36)].

Die vorstehende Ubersicht zeigt die Mannigfaltigkeit der zur Kultur und Diagnose der Meningokokken angewandten Hilfsmittel. Wollte man in jedem einzelnen Falle alle verschiedenen Nährböden in Grobrauch nehmen, so würde das den Gang der Untersuchung außerordentlich erschweren. Glücklicherweise ist das nicht nötig.

Die Verwendung von Aszitesagar zum Auffinden der Meningokokken wird nach wie vor die Grundlage des Meningokokkennachweises, vor allem bei Keimträgeruntersuchungen, bilden, da die Keime auf diesem leicht zu bereitendem Nährboden gut wachsen. Die Herauszüchtung der Meningokokken aus Rachenabstrichen mit Hilfe der Menschenblutagarplatte läßt zwar die Meningokokkenkolonien gegenüber andersartigen Kolonien augenfälliger hervortreten, hat jedoch bei Massenuntersuchungen den Nachtcil, die Augen rascher zu ermüden [Gassner (21)]. Fïr die Züchtung aus Lumbalpunktaten ist dagegen die Menschenblutagarplatte der Aszitesagarplatte zum mindesten gleichzustellen.

Optimales Wachstum der Meningokokken auf Aszitesagar wird nur dann erzielt, wenn der Aszitesgehalt genügend hoch gewählt wird. Mit 20prozentigem Aszitesagar konnte Gassner (21) höhere Prozente an Keimträgern ermitteln als mit Agar.geringeren Aszitesgehaltes, wie er anderweitig -zuweilen verwendet worden ist. Zur weiteren Verbesserung des Wachstums empfiehlt Zeissler (84) einen Zusatz von $2 \%$ Traubenzucker, der nach unseren Erfahrungen ein üpigeres Wachstum der Meningokokken ermöglicht, als der sonst übliche Glyzerinzusatz. Wir empfehlen deshalb zur Züchtung von Meningokokken einen Fleischwasser-(Hefewasser) Peptonagar mit 20\% Aszites und 2\% Traubenzucher.

Der Aszitestraubenzuckeragarplattenkultur kann nötigenfalls zur Anreicherung spärlicher Keime in Lumbalpunktat oder Blut cine Vorkultur in fliissigem Medium [Obé (59): wẻnig 10prozentige Traubenzuckerlösung, Schwenke (70): $3 \mathrm{ccm}$ Venenblut, in Bouillon, Ernst Fränikel (17): Aszitesbouillon] vorgeschaltet werden. Auf Grund eigener günstiger Er- 
fahrungen empfehlen wir selbst zur Anreicherung einen Zusatz von $1 / 2$ bis $1 / 3$ Volum 10prozentiger Traubenzuckerbouillon. Natürlich muB die Bebrütung der Vorkultur bei $37^{\circ}$ nicht, wie v. Tabora (77) angibt, bei Zimmertemperatur erfolgen, da bei letzterer keine Meningokokken, sondern höchstens Verunreinigungen wachsen.

Ein Ersatz der Aszitesflüssigkeit durch „frisches Rinderserum“ wird von Klinger und Fourman (47) vorgeschlagen; eine Nachprüfung dieser Angabe erscheint wünschenswert, da Gassner (21) mit der Verwendung von steril gewonnenem Pferdeserum überaus sehlechte Erfahrungen gemacht hat. Dem von Lloyd (55) vorgeschlagenem Ochsenherzblutagar und dem Eiereiweißagar von Sacquépée und Delater (66) dürfte schon im Hinblick auf die Schwierigkeit ihrer Herstellung keine praktische Verwendbarkeit zugesprochenwerden können; außerdem liegt kein Bedürfnis vor, den einfach herzustellenden Aszitesagar durch derartig komplizierte Nährböden zu ersetzen.

Für die Differentialdiagnose hat die Aszitesagarplatte nur einen beschränkten Wert, wenn auch von allen Autoren das Aussehen der Mcningokokkenkolonien auf diesem Nährboden übereinstimmend geschildert wird. Neben dem Aussehen ist die Konsistenz der Kolonien ein wichtiges Merkmal. Hancken (35) weist mit Recht nochmals darauf hin, daß sich Kolonien von Micrococcus pharyngis siceus und Micrococcus catarrhalis dadurch von den Meningokokken unterscheiden, daß sie sich nur in toto oder in Schollen abheben lassen. Auch wir haben regelmäßig diese Erfahrung gemacht.

Auf den Wert der zur Meningokokkenbestimmung herangezogenen v. Ling el sheim schen Zuckernährböden muß ausführlicher eingegangen werden. Einige Autoren wie Darré und Du mas(10), Isaak(44), Schwenke(70) erwähnen keine Schwierigkeiten bei der Benutzung dieser Nährböden. Fromme und Hancken(19) stellen die bakteriologische Diagnose ebenfalls nach ,den üblichen, eigentlich erst von v. Lingelsheim gegebenen Grundsätzen"; Hancken (35) selbst erhebt allerdings in einer gleichzeitig erschienenen Arbeit insoweit Bedenken, als er nur Dextrose und Lävulose zuverlässig fand, nicht aber Maltose, so daß er nur mit der ,Einschränkung der Maltoseverwertung die Zuckerreaktion für ein außerordentlich wertvolles Mittel zur Untersiützung der Meningokokkendiagnose" hält. Mit dem Hanckenschen Vorschlag, sich lediglich auf die Dextrose- und Lävuloseprüfung zu beschränken, fällt natürlich die Möglichkeit der Unterscheidung zwischen Meningokokken und Gonokokken fort. Die Versuche von Harzer und Lange (36) lassen keine bestimmten Schlüsse über die Brauchbarkeit der Zuckernährböden zu, da sich die Angaben dieser Autoren nicht auf wirkliche Meningokokken beziehen. Wohl dagegen gestatten die Ergebnisse der sehr eingehenden Untersuchungen von Klinger und Fourman 
(47) ein Urteil über die Brauchbarkeit der v. Lingelsheimschen Nährböden. Es sei hier nur darauf hingewiesen, dab von 9 aus dem Liquor von Meningitiskranken gezüchteten Stämmen sich nur 2 wie Meningokokken verhielten, die anderen 7 dagegen Maltose nicht vergärten, also als Gonokokken hätten diagnostiziert werden müssen! Wir selbst sind ebenfalls bei der Verwendung der v. Lingelsheimschen Nährböden auf Widersprïche gestoßen, indem insbesondere die Maltose kein einheitliches Verhalten der Meningokokken erkennen ließ, aber auch vereinzelt bei den anderen Zuckerarten das Ablesen der Reaktion nicht immer eindeutig möglich war, weil zuweilen innerhalb des gleichen Impfstrichs ohne erkennbare Ursache bald eine Rötung, bald ein Ausbleiben derselben beobachtet wurde. Es läßt sich vorläufig nicht entscheiden, welche Umstände hier mitsprechen. Wir müssen damit rechnen, erstens, daß der verwendete Zucker doch noch geringe Beimengungen anderer Zuckerarten enthält und zweitens, daß eine schwache Spaltung des Zuckers bei dem notwendigen Kochen oder nachher eintritt. Vielleicht auch bedingen die bei der Nährbodenzusammensetzung unvermeidlichen Schwankungen des Fiweißgehaltes, der ja vor allem wegen desZusatzes von Aszites ganz unbestimmbar ist, Verschiedenheiten des Bildes; wir dürfen auf das Verhalten der Bakterien der Typhus-Coli-Gruppe veı weisen, die bei gleichem Zuckergehalte des Nährbodens Säurebildung nur dann zeigen, wenn der EiweiBgehalt kein zu hoher ist [Gassner (22-24)]. Für die v. Lingelsheimschen Nährböden ist noch nicht nachgewiesen, daß das Verhältnis Zucker:Eiweiß wirklich das richtige ist, um eindeutige Ergebnisse zu gewährleisten. Dieser Nachweis ist vor allem darum nötig, weil nach den entsprechenden Beobachtungen mit Typhus-Colikeimen auch die Frage der Ablesungszeit in gewissen Umfang davon abhängt, ob das Verhältnis Eiweiß:Zucker optimal ist. Die für die v. Lingelsh eimschen Nährböden vorgeschriebene Ablesungszeit nach 24 Stunden ist oft nicht ausreichend. Thre Verlängerung halten wir jedoch erst dann für zulässig, wenn genügendes Beobachtungsmaterial über das Verhalten der verschiedenen gramnegativen Kokken bei langer Bebrütungszeit vorliegt.

Wir haben oben auch deshalb auf das Verhalten der Typhus-Colikeime hingewiesen, weil die einzelnen Stämme dieser Bakterienarten untereinander noch gewisse Schwankungen des Säurebildungsvermögens aufweisen; bekannt ist ja auch die Existenz von Colistämmen, die Lackmuslaktoseagar nicht röten. Wir müssen mit der Möglichkeit rechnen, daß die einzelnen Meningokokkkenstämme ähnliche Schwankungen des Zuckergärungsvermögens aufweisen; dann aber können allein schon aus diesem Grunde die v. Lingelsheimschen Nährböden nicht immer zuverlässig sein. 
Es harren also noch eine ganze Reihe prinzipiell wichtiger Fragen der I,ösung. Im Hinblick hierauf und auf die oben erwähnten von anderen Autoren gefundenen Widersprüche muB vorläufig vor zu hoher Bewertung der v. Lingelsheimschen Zuckernährböden, wie wir sie z. B. bei Fromme und Hancken (19), Isaak (44) noch finden, gewarnt werden; von ihrer Benutzung kann sogar ganz Abstand genommen werden, wenn man sich, wie wir unten vorschlagen, der Menschenblutagarplatte als entscheidenden differentialdiagnostischen Nährbodens bedient.

Hancken (35) läßt, ,aus praktischen Gründen den Gonococeus aus der Diagnose fort" und kann deshalb unter Verzicht auf Maltose sich ,lediglich auf dic Dextrose- und Lävuloseprüfung beschränken". Tun wir dies, so leistet die Menschenblutagarplatte durchaus nicht weniger als die Zuckernährböden, im Gegenteil, die Diagnose ist leichter, einfacher und unter allen Umständen zuverlässig. Fs ist schwer verständlich, daß die von Schottmiuller (69) schon im Jahre 1905 für die Meningokokkendiagnose eingeführte Menschenblutagarplatte trotz ihrer hervorragenden Eigenschaften von so gut wie keinem der neueren Autoren angewendet wird und den meisten überhaupt unbekannt zu sein scheint.

Bei der so gut wie allgemeinen Unbekanntheit der Menschenblutagarkultur und ihrer tatsächlichen Bedeutung soll das nach der von Schottmüller (69), Zeissler (84) gegebenen Schilderung charakteristische Wachstum der Meningokokken auf diesem Nährboden hier nochmals beschrieben werden. Die auf Menschenblut-Traubenzuckeragar oberflächlich gewachsenen Meningokokkenkolonien sind im allgemeinen kreisrund. Ihr Durchmesser sehwankt zwischen $1 \mathrm{~mm}$ (nach 24stündiger Bebrütung) und $6 \mathrm{~mm}$ (nach mehrtägiger Bebrütung). Kleinere Kolonien eiheben sich ètwa 1/2 mm, größere bis $1 \frac{1}{2} \mathrm{~mm}$ über den Nährboden; letztere sind nicht kuppel- oder kegelförmig, sondern plattenförmig und tragen manchmal knopfförmige Auflagerungen. Die Oberfläche der Kolonien zeigt einen matten Glanz. Ihre Farbe ist stets grauviolett und wird von Schottmüller (69) treffend mit der auf die Blutplatte versprengter Milchtröpfchen verglichen. Jede Verwechslung mit Kolonien des Micrococcus crassus, des Diplococeus flavus und anderer Kokkenarten aus dieser Gruppe wird durch das charakteristische Aussehen der Meningokokkenkolonien mit Sicherheit vermieden. Die Konsistenz der Meningokokkenkolonien entspricht der von wasserarmem Kartoffelbrei, ist also schmalrig und unterscheidet sie dadurch streng von den im übrigen ähnlich aussehenden Kolonien des Micrococcus catarrhalis. Einzig und allein von Gonokokkenkolonien unterscheiden sich die Meningokokkenkolonien auf der Menschenblut-Traubenzuckeragarplatte nicht oder kaum. 
Die von Schottmüller (69) vorgeschlagene Menschenblutagarplatte enthält keinen Traubenzucker. Der von Zeissler $(84,85)$ empfohlene Zusatz von $2 \%$ Traubenzucker bedingt ein üppigeres Wachstum der Kolonien gegeniuber dem Schottmüllerschen Originalblutagar obne jede Beeinträchtigung des für die Meningokokken charakteristischen Bildes. Zur Herstellung des Blutagars empfehlen wir also einen Fleisch-(Hefe)wasser-Peptonagar mit 2\% Traubenzucker und $20 \%$ steril entnommenem Menschenblut, letzteres dem etwa $45^{\circ}$ warmen flüssigen Nähragar zugefügt und guit durchgemischt.

Die Gewinnung des Blutes erfolgt am besten durch Venenpunktion mit trocken sterilisierter Kanüle und großer ebenfalls trocken sterilisierter Luerscher Spritze; im Notfall kann von der Verwendung der letzteren abgesehen werden. Der Einwand, dab Menschenblut nicht immer leicht und in genïgender Menge zu beschaffen sei, spielt gegenüber den besonderen Vorzügen des Menschenblutagars keine Rolle. In Krankenhäusern ist zudem meist genug Anlaß zu Blutentnahmen; im übrigen dürfte es nicht schwierig sein, bei den so häufigen Wassermannuntersuchungen dem Patienten etwas mehr Blut abzunehmen und den Uberschuß zu Blutplatten zu verarbeiten. Mangel an Menschenblut zur Nährbodenbereitung ist nach unseren Erfahrungen bei ernstlichem Willen des Institutsleiters nicht $z u$ befürchten.

Nach dem oben Gesagten ermöglicht die Menschenblutplatte die Differentialdiagnose bis auf die Unterscheidung zwischen Meningokokken und Gonokokken. Auf diese Unterscheidung wird von vielen Autoren, z. B. Hancken (35), wenig Wert gelegt; will man sie aber doch auf kulturellem Wege herbeiführen, so genügt das ťberimpfen der fraglichen auf Menscheneiweiß haltigen Nährböden (Aszites- oder Blutagar) gewonnenen Kulturen auf gewöhnlichen Agar und in gewöhnliche Bouillon. Kokken, welche schon nach ein bis zwei Generationen nicht nur auf Aszites-und Blutagar, sondern auch auf gewöhnlichem Agar bzw. in Boullon ohne Zusatz von Menschèneiweib wachsen, sind keine Gonokokken.

Die auch heute noch zuweilen [Hancken (35)] zur Unterscheidung der Meningokokken von verwandten Keimen herangezogenen Kulturversuche bei niederen Temperaturen können bei Benutzung der Menschenblutplatte fortfallen. Ebenso kann auf die Verwendung von Gelatinenährböden [Harzer und Lange (36) u. a.] verzichtet werden. Das von einigen Untersuchern [Ghon (25), Hancken (35)] diagnostisch als besonders wertvoll bezeichnete Loefflerserum bietet gegenüber der Menschenblutplatte keinerlei Vorteile; Flavusstämme u. a. von Meningokokken abzutrennen, ist auf der letzteren viemehr leichter möglich als auf Loefflerserum. 
So kann auf die Anwendung einer ganzen Reihe bisher zurMeningokokkendiagnose verwendeter Nährböden verzichtet und der kulturelle Meningokokkennachweis in folgender Weise vereinfacht werden:

A. Untersuchung von Rachenabstrichen.

1. Herauszüchtung und Isolierung: Aszitestraubenzuckeragarplatte.

2. Kulturelle Prüfung: Menschenblut-Traubenzuckeragarplatte.

B. Untersuchung von Lumbalpunktaten, Exsudaten usw.

1. Anreicherung:

Zusatz von 10 prozentiger Tra ubenzucker-Bouillon und Bebrütung bei $37^{\circ}$.

2. Herauszüchtung und Isolierung: Aszitestraubenzuckeragarplatte oder Menschenblut-Traubenzuckeragar platte.

3. Kulturelle Prüfung:

Menschenblut-Traubenzuckeragarplatte.

C. Untersuchung des strömenden Blutes.

Herauszüchtung, Isolierung und kulturelle Prüfung:

Menschenblut-Traubenzuckeragarplatte. (4 Teile Traubenzuckeragar und 1 Teil Krankenblut: Geringste Blutmenge $30.0 \mathrm{ccm}$.)

In bezug auf weitere technische Einzelheiten der Blutentnahme sei auf Zeissler und Riedel (84) verwiesen.

Zur Differenzie. rung gegen Gono. kokken: Überimp. fen in zweiter bis dritter Generation auf gewöhn-

lichen Agar und in gewöhnliche Bouillon.

Die vorstehende Utbersicht zeigt, wie einfach im Grunde der Meningokokkennachweis ist, wenn man sich der Menschenblutplatte als entscheidenden Nährbodens bedient. Dab der so geführte Nachweis an Zuverlässigkeit nichts zu wünschen übrig läßt, geht schon aus den klassischen Untersuchungen Schottmüllers (69) hervor.

Uber den Wert eines rein kulturellen Nachweises der Meningokokken sind die Anschaungen der verschiedenen Untersucher sichtlich geteilt. In -einer Reihe von Arbeiten: Bittorf (3), Eug. Fränkel(18); Götz und Hanfland(30), Küster und Günzler(52), Pick(62), Rosenbaum(64), Silbergleit und Angerer [71], Stephan [74]) wird die Diagnose, abgesehen vom mikroskopischen Präparat, ausschlieBlich auf die Kultur gegründet. Die Mehrzahl der Autoren: Börnstein (5), Darré und Dumas (10); Dopter 
und Pauron (12-14), Fromme und Hancken (19), Gassner (21), Ghon (25), Hancken (35), Harzer und Lange (36), G. Herzog (37), Jochmann (45), Justitz (46), Klinger und Fourman (47), Köhlisch (48), Schwenke(70), Svestka (76), ,Times"(78), Wollstein(83), Zeissler und Riedel (84), zieht aber auch den serologischen Nachweis zur Diagniose heran und hält ihn z. T. für den „Schlußstein der Diagnose“" [Hancken (35)].

Ein Vergleich der von den verschiedenen Autoren erhaltenen Ergebnisse von Agglutinations- und Komplementbindungsversuchen zeigt nur das eine mit Sicherheit, daß wir hier nicht mit so eindeutigen Verhältnissen, wie z.B. bei den serologischen Reaktionen der Typhus--und Cholerakeime, rechnen können. Zwar muß zugegeben werden, daß die auf Meningokokken bezïglichen Untersuchungen der letzten Jahre technisch nicht immer einwandfrei durchgeführt sind. So stellen Fr o mme und Hancken(19) eine positive Diagnose bei Ausflockung 1: 100 mit einem Serum vom Titer 1:800 bis 1:1000. Hancken (35) selbst bewertet sogar bei dem gleichen Serumtiter noch eine Ausflockung 1:50 als positive Agglutination, wobei noch zu berücksichtigen ist, daß Kontrollen mit Normalserum der gleichen Tierart und z. T. anseheinend auch mit Kochsalzlösung fehlen. Aus der Arbeit ist ferner nicht zu ersehen, ob die berichteten positiven Agglutinationen von Flavus-, Siccus-, Catarrhalis- und Crassusstämmen durch ausreichende Kontrollen vor Verwechslung mit Spontanagglutinationen gesichert sind. Svestka(76) stellt ebenfalls ,die klinische und bakteriologische Diagnose: Meningitis cerebrospinalis epidemica auf Grund einer

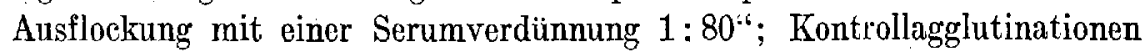
und Titerangabe des verwendeten Serums fehlen. Klinger und Fourman(47) sind so vorsichtig, auf ihre mit Verdünnungen 1:50 und 1:100 eines ,hochwertigen" Serums (Titerangabe fehlt) erhaltenen Ergebnisse keine Rückschlüsse auf die Meningokokkennatur der von ihnen untersuchten Stämme zu ziehen. Jochmann (45) verlangt Ausflockung, in hohen Verdünnungen eines hochwertigen Serums".

In einer ganzen Reihe von Fällen ist also teils mit relativ konzentrierten, von der Titergrenze weit entfernten Serummengen, teils ohne Kontrolle in Kochsalzlösung bzw. Serum der gleichen Tierart der serologische Nachweis zu führen versucht worden. Da aber bei der Agglutination der Meningokokken besonders schwierige Verhältnisse vorliegen, genügt diese Art der serologischen Prüfung den an die Technik solcher Untersuchungen zu stellenden Ansprüchen nicht. Es muß. vielmehr, wie schon Zeissler (84) ausgeführt hat, verlangt werden, daß erstens die Ausflockung bis nahe an die Titergrenze herangeht, zweitens die Kokken in physiologischer Kochsalzlösung ohne Serumzusatz und drittens in 
normalem Serum derselben Tierart von welcher das agglutinierende Serum stammt, im Fünffachen der Konzentration, in welcher letzteres noch agglutiniert, keine Spontanagglutination zeigen. Die Spontanagglutination ist vor allem eine charakteristische und sehr konstante Eigenschaft des dem Meningococcus nahe verwandten Micrococcus catarrhalis.

Für die nur orientierende Mikroagglutination ist es natürlich gestattet, mit konzentrierteren Lösungen zu arbeiten, jedoch dürfen die so erhaltenen Ergebnisse für das Endurteil nicht schlechthin maßgebend sein. Mit einem ungewöhnlich hochwertigen, aus dem Rostocker Hygienischen Institut bezogenen Serum (Titer 1:3200) hat zwar bei Gassner (21) die Mikroagglutination bei mehrfacher Nachprüfung zu dem gleichen Ergebnis geführt wie die exakte Austitration; doch betont Gassner(21) selbst, daß er die günstigen Ergebnisse der Mikroagglutination nur mit diesem einen Serum, dagegen nicht mit anderen, vom Kaiserlichen Gesundheitsamte bezogenen Seren erzielte.

Wenn wir berücksichtigen, daß in den weiter oben angeführten Agglutinationsversuchen vielfach nicht alle Fehlerquellen durch ausreichende Kontrollen ausgeschlossen sind, und daß durch die Möglichkeit der fälschlichen Einbeziehung unspezifischer Ausflockungen und Anwendung zu konzentrierter Serumlösungen in Wirklichkeit zu hohe Prozentzahlen positiver Fälle ermittelt sein dürften, so ergeben doch auch diese Arbeiten, daß die Agglutination mit spezifischem Serum bei den verschiedenen untersuchten Meningokokkenstämmen durchaus keine regelmäßige Erscheinung ist. Sogar unter den oben angeführten zu liberalen Versuchsbedingungen ergaben sich hin und wieder sonst typische Stämme, die durch Meningokokkkenserum nicht zur Agglutination zu bringen waren. Hancken ( 35 berichtet über Versagen der Agglutination in einigen Fällen, und Klinger und Fourman(47) finden eine starke bis deutliche Agglutination nur bei zwei von fünf $\mathrm{Me}$ ningokokkenstämmen, die sie aus dem Liquor von Meningitiskranken herausgezüchtet hatten. Die Verfasser heben daher „die Tatsache der schlechten Agglutinierbarkeit vieler Meningokokkenstämme" ausdrücklich hervor. Besonders lehrreich ist weiter, daB die von denselben Autoren vergleichend durchgeführten Komplementbindungsversuche in ihren Ergebnissen mit den Agglutinationsversuchen weitgehend differieren. Da aber auch die Komplementbindungsversuche mit der kulturellen Prüfung keineswegs übereinstimmten, gestattete auch die Komplementbindung ,eine sishere Diagnose aller Meningokokkenstämme nicht".

Rechnet man nur die Ergebnisse derjenigen Agglutinationsversuche als positiv, bei denen die Ausflockung bis in die Nähe der Titergrenze des Serums erfolgt, und unspezifische Ausflockungen ausgeschlossen sind, so 
dürften die berichteten positiven Fälle noch wesentlich zusammenschrumpfen. Zeissler und Riedel(84) erwähnen einen negativ ausgefallenen exakt austitrierten und durch ausreichende Kontrollen gesicherten Agglutinationsversuch mit einem echten Meningokokkenstamm. Auch Gassner (21) berichtet über Stämme, die aus dem Liquor von Meningitiskranken gezüchtet waren, und die teils gar nicht, teils mit nur einem der beiden angewandten Sera agglutinierten.

Die Herkunft und Beschaffenheit der Sera muß überhaupt bei der Beurteilung der Agglutinationsversuche in höherem Maße als es bis jetzt geschieht, berücksichtigt werden. Klinger und Fourman (47) erwähnen bereits Beobachtungen, die in diesem Sinne sprechen. Gassner (21) hat mit dem aus. Rostock bezogenen Serum (Kaninchenserum) an den gleichen Meningokokkenstämmen ganz andere Ergebnisse erhalten als mit dem aus dem Kaiserlichen Gesundheitsamt stammenden Serum (Eselserum); es ist nicht unwahrscheinlich, daß sich die verschiedenen Tierarten für die Gewinnung von agglutinierendem Meningokokkenserum ungleich eignen. Das Berliner Serum gab einerseits wesentlich weniger einwandfreie positive Agglutinationen als das Rostocker und neigte andererseits mehr zu unspezifischen Ausflockungen.

Die Tatsache, daß die gleichen Meningokokkenstämme ein verschiedenartiges Verhalten gegenüber den beiden von Gassner(21) verwendeten Seren zeigten, dürfte damit in Zusammenhang zu bringen sein, daß das Berliner und Rostocker Serum mit verschiedenen Meningokokkenstämmen hergestellt sind. Die Beobachtungen deuten dann darauf hin, dab die einzelnen Meningokokkensera jeweils nur einen bestimmten kleineren oder größeren Kreis von Meningokokkenstämmen und zwar vermutlich solchen, die dem Antigenstamm des Serums nahe stehen, agglutinieren.

Hierfür sprechen auch die neueren Arbeiten französischer und englischer Autoren. Es sind unzweifelhaft serologische Unterschiede zwischen verschiedenen Meningokokkenstämmen vorhanden, und diese Unterschiede veranlassen die Autoren nach dem Vorgang von Dopter (11) 1909 zwischen „Meningokokken" und „Parameningokokken" zu unterscheiden. Darré und Dumas (10) isolierten aus Lumbalpunktaten zwei Kolkenstämme, die sie auf Grund ihres serologischen Verhaltens insbesondere im Castellanischen Versuch, als „Parameningokokken" ansprechen. Die weiteren Untersuchungen von Dopter und Pauron(12-14) zeigen nun aber, dab auch die sogenannten ,Parameningokokken" serologisch keine einheitliche Gruppe bilden; es wurden drei verschiedene Rassen $(\alpha, \beta, \gamma)$ festgestellt, die untereinander genau so große serologische Differenzen auf- 
weisen, wie sie seinerzeit zur Abtrennung der ,Parameningokokken“" von den sogenannten ,echten Meningokokken" gefühirt hatten.

So hätten wir also nach diesen Autoren neben "Meningokokken" vorläufig drei verschiedene Spezies ,Parameningokokken“. Meningokokken und „Parameningokokken" sind in gleicher Weise aus dem Liquor Meningitiskranker gezüchtet, sind also Stämme, die das gleiche klinische Krankheitsbild hervorrufen. Auch kulturell und morphologisch verhalten sie sich vollständig gleich. Nur die serologisehen Unterschiede können zur Abgrenzung dienen; da aber die einzelnen Stämme der ,Parameningokokken“ sich serologisch gegeneinander genau so scharf abzcichnen wie die willkürlich aufgestellten Hauptgruppen der ,Meningokokken“ gegenüber den „Parameningokokken“, finden wir neuerdings bei Wollstein (83) das Bestreben, die Haupteinteilung in ,Meningokokken" und ,Parameningokokken" als ungenügend begrïndet fallen zu lassen und nur verschiedene Stämme von Meningokokken zu unterscheiden.

Die Aufstellung des Begriffes der „Parameningokokken“ ist auch schon im Hinblick auf die im Namen angedentete Analogie mit Paratyphus irreführend. Bei Typhus und Paratyphus liegen doch ganz andere Verhältnisse vor als bei Meningokokken und „Parameningokokken". Bei ersteren erschöpft sich die Unterscheidung eben nicht nur in serologischen Differenzen, sondern sie beruht vor allem in weitgehenden Unterschieden der klinischen Krankheitsbilder und ferner in sehr wesentlichen kulturell-biologischen Abweichungen. Auch mit der serologischen Differenzierung der verschiedenen Ruhrarten kann die Trennung zwischen ',Meningokokken“" und ,Parameningokokken" nicht in Parallele gesetzt werden, denn auch bei den Ruhrarten liggen wiederum vor allem sehr große Verschiedenheiten der klinischen Bilder und nicht minder deutliche kulturelle und biologische Unterschiede (Giftbildung nur bei Shiga-Kruse!) vor. Von alledem ist bei Meningokokken und „Parameningokokken" nicht die Rede, und darum sind wir nur berechtigt, zwischen ausschließlich serologisch unterscheidbaren Rassen von Moningokokken, dagegen nicht zwischen zwei verschiedenen Gattungen „Meningokokken“" und ,Parameningokokken“" zu unterscheiden. Ob der eine Stamm besser bei $37^{\circ}$, der andere besser bei $55^{\circ}$ agglutiniert wird, wie einige Autoren beobachtet zu haben angeben, hat mit der Frage, ob rein serologische Verschiedenheiten zur Aufstellung neuer Gattungen berechtigen, gar nichts zu tun.

Ohne Berücksichtigung der Arbeiten von Dopter (11), Dopter und Pauron (12-14), Darré und Dumas (10), Wollstein (83) bezeichnet Pollag (63) einen schleimbildenden Kapselkokkus als "Parameningokokkus", welcher nach der Beschreibung des Autors vom Meningococcus Weichsel- 
baum kulturell absolut verschieden ist. Er identifiziert ihn mit dem von Stephan $(74,75)$ unter dem Namen ,Diplococcus mucosus Leipzig“ beschriebenen angeblich gramnegativen Keim, welchen wiederum v. Lingelsheim (54) für identisch bält mit dem zuerst von ihm beschriebenen „Diplococcus mucosus". Nach Scheller(67) ist jedoch der Stephansche Kokkus nicht gramnegativ, sondern grampositiv und unterscheidet sich also auch hierdurch vom Meningococcus Weichselbaum. Die von Pollag gewahlte Benennung dieses Kokkus als „Parameningokokkus" ist zu verwerfen, weil die Bezeichnung Diplococcus mucosus die: altere ist, und weil die ohne Berücksichtigung des bisherigen Begriffs der Parameningokokken gewählte Bezeichnung .Parameningokokkus" nur geeignet ist, die auf diesem Gebiete jetzt bestehende Verwirrung noch zu vergrößern.

Die Tatsache des Vorhandenseins serologisch verschiedener Rassen von Meningokokken geht auch aus einem von ärztlicher Seite stammenden Aufsatz in den Times vom 22. 1. 17 hervor, der durch das Kgl. preuß. Kriegsministerium den militärärztlichen Behörden zur Kenntnisnahme übcrwiesen wurde (78). Danach handelt es sich nicht, ,um eine Bakterie, sondern um vier verschiedene Typen dieser Art": Auf die daran geknüpften Ausfïhrungen über die Behandlung mit spezifischen Seren soll hier nicht weiter eingegangen werden.

Aus dem Vorhandensein serologisch verschiedener Rassen von Meningokokken ergibt sich für die pralktische Meningokokkondiagnose, dab von einem bestimmten agglutinierenden Meningokokkenserum nur die jeweils dem betreffenden Antigenstamm serologisch nahestehenden Stämme agglutiniert werden können. Solange wir nicht absolut polyvalente Sera haben, können darum aus einem etwaigen negativen Ausfall des Agglutinations- bzw. Komplementbindungsversuches auf die Meningokokkennatur des untersuchten Stammes keinerlei Schlüsse gezogen werden. Negative Agglutinationsergebnisse sind also unter keinen Umständen beweisend. Andererseits muß bei positiver Agglutination strengstens darauf geachtet werden, daß die weiter oben angegebenen Vorsichtsmaßregeln jede Möglichkeit einer Täuschung ausschließen. Hierdurch dürfte freilich die Zahl derjenigen Fälle, in welchen die Agglutination zur Stiutzung der Diagnose herangezogen werden kann, eine weitere Verminderung erfahren.

Da also bei dem gegenwärtigen Stand unserer Kenntnis von der Agglutination der Meningokokken ein positiver Ausfall derselben von vornherein von dem Zufall des Besitzes eines für den jeweils zu untersuchenden unbekannten Stamm geeigneten Serums abhängig ist, kann der serologische Nachweis keinesfalls als ,Schlußstein der Diagnose "[Hancken (35)] verlangt werden. Vielmehr $m u B$ auch heute noch die Diagnose auf den exakten Nachweis durch. Kultur gegründet werden. 
Eine etwaige positive Agglutination liefert natürlich eine erfreuliche, keineswegs aber unbedingt notwendige Bestätigung des kulturellen Nachweises. Nur falls es je möglich sein sollte, wirklich für alle bekannten und möglichen Meningokokkenrassen agglutinierende Sera nebeneinander zur Verfügung zu haben, könnte dem serologischen Nachweis eine größere Bedeutung zuerkannt werden.

Die bisherige vielfache Überschätzung des serologischen Nachweises für die Meningokokkendiagnose, z. T. im Verein mit einer ungenügenden Technik der Agglutinationsuntersuchungen ist einer der Gründe für die bestehende Unsicherheit und die vielfachen Widersprüche in der Meningokokkendiagnose. Selbstverständlich haben die weiter oben wiedergegebenen Unterschiede des mikroskopischen und kulturellen Nachweises in den Angaben der einzelnen Autoren auch nicht zur Klärung der Verhältnisse beigetragen. Vergleichen wir z. B. die grundlegenden und zu eindeutigen Eigebnissen führenden Untersuchungen Schottmüllers (69) mit einer der modernen Arbeiten, z. B. Hancken (35), Klinger und Fourman (47), u. a. [von Köhlisch (48), H. Fischer (16), A. Jaiser (42) zu schweigen]. so können wir wirklich nicht von einem Fortschritt in den Jahren 1905 bis 1915/17 auf dem Gebiete der Diagnose der Meningokokken reden. Es ist alles unsicher geworden. Auch die sorgfältigeren Untersucher vermögen eine klare Umschreibung der für Meningokokken spezifischen Eigenschaften nicht zu geben. „Wir besitzen vorläufig kein den Meningokokken allein zukommendes stets vorhandenes Merkmal", sagen Klinger und Fourman (47). ,Typische Stämme können wir jederzeit leicht erkennen; handelt es sich aber um einen in einer oder mehreren Eigenschaften atypischen Stamm, so kann häufig eine sichere Diagnose nicht gestellt werden. Nur die Herkunft desselben wird hier in manchen Fällen eine Entscheidung ermöglichen." Und entsprechend sagt Hancken (35): ,Wir kennen z. Zt. keine absolut beweisende Eigenschaft des Meningococcus, die zur Dia gnosestellung allein verwertbar ist." Zur Kennzeichnung der zurzeit herrschenden Verwirrung sei noch erwähnt, daß der eine der Verfasser [Gassner(21)] cine Reihe von ihm als Weichselbaumsche Meningokokken best mmte Reinkulturen, die zuvor von Prof. Pfeiffer (Rostock), Dr. Zeissler (Altona) und Prof. Schottmüller (Hamburg) übereinstimmend als solche bestätig waren, zur weiteren Begutachtung an die Kaiser WilhelmAkademie (Berlin) sandte und von dort den Entscheid erhielt, daß von den 11 Stämmen ,,nur eine Kultur bei der Nachprüfung als Meningokokkenkultur anerkannt werden konnte."

So kann es nicht wundernehmen, wenn die jetzige Unsicherheit der bakteriologischen Meningokokkendiagnose wenig kritisch veranlagte Unter- 
sucher zu falschen Ergebnissen und Schlüssen geführt hat. Einen Höhepunkt in dieser Richtung bedeuten die Untersuchungen von Köhlisch (48), die nach den eigenen Worten ihres Autors ,nichts Abgeschlossenes, Ausgereiftes" bringen, jedoch nicht immer als das bewertet werden, wofür der Autor selbst sie bewertet sehen möchte. Im Interesse der Sache muB einmal klar ausgesprochen werden, daß die Ausführungen Köhlischs nicht verdienen, als ernsthaft berücksichtigt zu werden. Die Gramfärbung ist falsch, was zu eine unrichtigen Beurteilung des Gramverhaltens der untersuchten Kokken führen muB. Die Beurteilung morphologischer Merkmale ist ebensowenig einwandfrei. Der Verfasser fand z. B. ,Kokken, aber Meningokokken waren es nicht, es waren vielmehr Streptokokken von anscheinend ganz charakteristischem und spezifischem Verhalten. Schon im mikroskopischem Präparat lagen sie in Haufen zusammen", und die weitere Schilderung zeigt das eine mit Sicherheit, daß die beobachteten "Streptokokken" etwas ganz anderes gewesen sind. Die kulturellen Untersuchungen kranken vor allem daran, daB sichtlich nicht mit Reinkulturen gearbeitet worden ist. Mischkulturen, aus denen die einzelnen Komponenten herauswachsen, sind die Grundlage seiner „Mutations"forschung. Nicht weniger bedenklich sind die Ausführungen über ,Mutationen" im Tierkörper und im Körper des Kranken, in denen nach Belieben Meningokokken in Streptokokken „mutieren" und umgekehrt. In Wirklichkeit handelt es sich, soweit die Mitteilungen von Köhlisch (48) überhaupt ein Urteil gestatten, bei dem berichteten Fall um eine Meningokokkenmeningitis mit gleiehzeitiger Mischinfektion durch eine andere, auf Grund der vorliegenden Angaben nicht bestimmbare Kokkenart. Derartige Mischinfektionen sind längst bekannt und auch neuerdings wieder mehrfach beschrieben (D uhot et Boez (15), Gaethgens (20), Goetz und Hanfland (30), Silbergleit und Angerer(71)). Sie haben allerdings noch nicht zur Aufstellung ,"vager Hypothesen", wie Köhlisch (48) selbst von seinen eigenen Ausführungen sagt, geführt.

Das Beispiel von Köhlisch scheint leider. Schule zu machen. H. Fischer (16) und A. Jaiser (42) diskutieren bei dem von ihnen beobachteten Fall einer Mischinfektion bei Meningitis nunmehr ebenfalls die Möglichkeit einer ,,Mutation". Das Bedenkliche der Arbeit von Köhlis eh (48) scheinen diese Autoren nicht erkannt zu haben, sonst hätten sie nicht gerade diese Arbeit als Kronzeugen von Mutationshypothesen angeführt und wären vielleicht auch in dem Vergleich des von ihnen als Krdnkheitserreger gefundenen „Diplococcus flavus" der dem von Köhlisch gezüchteten ,Streptokokkus:" ,in allem... fast aufs genaueste gleicht, vielleicht mit ihm identisch ist" vorsichtiger gewesen. 
Die gegen die Untersuchungen von Köhlisch (48) zu erhebenden Bedenken lassen sich nun allerdings nicht ausschließlich auf die bisherigen Mängel der Meningokokkendiagnostik zurückführen; denn Köhlischs Ausführungen verdanken ihre Entstehung auch dem Mangel bakteriologischer Schulung. Andererseits wären die vorgekommenen Entgleisungen doch vielleicht weniger schwer geworden, wenn die Meningokokkendiagnostik nicht wie bisher in erster Linie von dem Gutdünken des einzelnen Untersuchers, sondern von bestimmten, allgemein anerkannten Richtlinien abhinge. Das Fehlen einer allgemein anerkannten Diagnostik wird ja gerade in den sorgfältigen Arbeiten von den Autoren selbst als Mangel empfunden, in gleiche: Weise aber auch von dem Leser, denn nur cine gleichmäßige, einheitliche Diagnostik ermöglicht einen einwandfreien Vergleich der von den verschiedensten Seiten ausgeführten Untersuchungen. So unterliegt es gar keinem Zweifel, daß bei Keimträgeruntersuchungen die von verschiedenen Autoren gefundenen, weit divergierenden Prozentzahlen positiver Fälle nicht unwesentlich auch auf Versehiedenheiten der Untersuchungsmethode zurückzuführen sind, so daß sich den hygienisch-epidemiologischen Feststellungen von Keimträgern schon aus diesem Grunde nur ein sehr bedingter Wert zusprechen läßt.

Vereinheitlichung der diagnostischen Methodik ohne Beeinträchtigung ihrer Sicherheit ist das Ziel, nach dem wir streben müssen. Es ist in obigem in Hinblick auf die Untersuchungen der letzten Jahre ausgeführt, daß eine solche Vereinheitlichung nicht nur wünschenswert, sondern auch möglich ist, und daß die zu verlangende Sicherheit der Diagnose unter der gleichzeitigen Vereinfachung nicht im geringsten Ieidet, im Gegenteil, durch den Fortfall entbehrlicher und nur beschränkt leistungsfähiger Hilfsmittel ein beträchtlicher Fortschritt erzielt wird.

Der eindeutige und, soweit heute möglich, einfachste Nachweis des Meningococcus Weichselbaum würde sich nach den obigen Ausführungen folgendermaßen gestalten:

\section{Allgemeine Methodik.}

I. Mikroskopische Prüfung durch Gramfärbung.

II. Kulturelle Prüfung:

a) Menschenbluttraubenzuckeragarplatte,

b) gewöhnlicher Agar.

c) gewöhnliche Bouillon.

Stets

zu verlässig.

III. Serologische Prüfung durch Agglutination, oft versagend. 


\section{Durchführung der Untersuchung.}

A. Untersuchung von Rachenabstrichen.

1. Herauszüchtung und Isolierung: Aszitestraubenzuckeragarplatte.

2. Mikroskopische Prüfung der Kolonicen: Gramfärbung.

3. Kulturelle Prüfung:

a) Menschenblut-Traubenzuckeragarplatte,

b) gewöhnlicher Agar,

c) gewöhnliche Bouillon.

4. Serologische Prüfung durch Agglutination.

B. Untersuchung von Lumbalpunktaten, Exsudaten usw.

1. Mikroskopische Untersuchung im Grampräparat direkt und ev, nach Anreicherung mit Traubenzuckerbouillon.

2. Herauszüchtung und Isolierung: Aszitestraubenzuckeragarplatte oder Menschenblut. Traubenzuckeragarplatte.

3. Mikroskopische Prüfung der Kolonieen: Gramfärbung.

4. Kulturelle Prüfung:

a) Menschenblut-Traubenzuckeragarplatte,

b) gewöhnlicher Agar,

c) gewöhnliche Bouillon.

5. Serologische Prüfung durch Agglutination.

C. Untersuchung des strömenden Blutes.

1. Herauszüchtung und Isolierung mittels

Menschenblut-Traubenzuckeragarplatte (Traubenzuckeragar und Krankenblut).

2. Mikroskopische Prüfung der Kolonieen: Gramfärbung.

3. Kulturelle Prüfung:

a) Menschenblut-Traubenzuckeragar platte,

b) gewöhnlicher Agar,

c) gewöhnliche Bouillon.

4. Serologische Prüfung durch Agglutination.

a) Gramfärbung:

Technische Einzelheiten.

I. Anilinwassergentianaviolett: drei Minuten.

II. Lugolsche Lösung: zwei Minuten.

III. Alkohol, absol, bis keine Farbe mehr abläuft oder mit Fließpapier abgetupft werden kann.

IV. Nachfärbung mit verdünntem Karbolfuchsin oder Bismarckbraun. Einzelheiten bei Schmorl: Die pathologischhistologischen Untersuchungsmethoden. 7. Auflage. 1914, S.305 und 310 .

b) Anreicherung: Zusatz von einen halben bis ein Drittel Volumen 10prozentiger Traubenzuckerbouillon und Bebrütung bei $37^{\circ}$. 
c) Aszitestraubenzuckeragar: Nähragar mit 2\% Traubenzucker und $20 \%$ Aszites.

d) Menschenblut-Traubenzuckeragar: Nähragar mit 2\% Traubenzucker und 20\% Menschenblut (vergl. Seite 301 und 302).

e) Gewöhnlicher Agar oder Glyzerinagar.

f) Gewöhnliche Bouillon.

g) Ausführliche Agglutination:

I. Agglutinierendes Serum in einfacher, zweifacher, vierfacher, achtfacher Titerdosis.

II. Normales Serum derselben. Tierart, je im Fünffachen obiger Serumkonzentrationen.

III. Physiologische Kochsalzlösung.

h) Orientierende Mikroagglutination:

I. Agglutinierendes Serum im 10 bis 50 fachen der Titerdosis.

II. Normales Serum derselben Tierart im Doppelten vorstehender Serumkonzentrationen.

III. Physiologische Kochsalzlösung.

Mikroagglutination nur mit sehr hochwertigem Serum ratsam. Ergebnis durch Makroagglutination bestätigen.

Dic Durchführung der Untersuchung auf Meningokokken ist, wie die Zusammenstellung zeigt, je nach dem zu untersuchenden Material etwas verschieden. Wesentlich ist ferner, daß positiver Kokkennachweis je nach der Fundstelle verschieden bewertet wird. In dieser Hinsicht liegen auch aus jüngster Zeit hie und da Angaben vor, die nicht ohne Widerspruch bleiben dïrfen. So wird die klinische Diagnose ,Meningokokkenmeningitis" zuweilen ausschließlich oder zunächst auf Grund positiver Rachenbefunde gestellt [Hochhaus.(39, Svestka (76)], wo doch ebensowohl gesunde Keimt äger eine häufige Erscheinung sind als auch über Moningitiskranke ohne Meningokokken im Rachen berichtet ist [Gassner (21)]. Rachenabstriche für die Diagnose einer Meningokokkenerkrankung in ganz leichten, klinisch unsicheren Meningitisfällen [Hochhaus (39)] oder in fraglichen Sepsisfällen heranzuzichen, ist nicht ratsam; vic mehr muB der Nachweis der Krankheitserreger für Meningitis aus dem Lumbalpunktat, für Bakteriämie und Sepsis aus dem Blut selbst geführt werden: [Gassner(21), Ghon (25,26), Goebel und Hess (28), Jochmann (45) Staehelin (73), Zeissler und Riedel (84)]. Wenn z. B. Bittorf(4), Köhlisch (48) mehrfach aus wiederholt negativen Blutkulturversuchen nur auf Grund positiven Liquorbefundes die Diagnose ,Meningokokkensepsis" stellen, so kann eine solche Diagnose nur den Wert einer Vermutung haben. 


\section{Literaturverzeichnis.} S. 454 .

1. v. Angerer, Diskussionsbemerkung. Deutsche med. Wochenschrift. 1915.

2. J. P. Bijl und R. N. M. Eykel, Meningitis cerebrospinalis epidemica. Tidschr. voor Geneesk. 1916.

3. A. Bittorf, Über septische Meningokokkeninfektion. Deutsche med. Wochenschrift. 1915. S. 1085.

4. Derselbe, Zur Kenntnis der Meningokokkensepsis. Münchener med. Wochenschrift. 1916. S. 951.

5. P. Börnstein, Ein Fall von epidemischer Genickstarre bei allgemeiner Miliartuberkulose. Zentralbl. f. Bakteriologie. Abt. I. Orig. 1917. Bd. LXXIX. S. 172 .

6. C. Brach und Jos. Fröhlich, Über die Serotherapie der epidemisehen Genickstarre. Wiener klin. Wochenschrift. 1915. S. 529.

7. H. A. Bray, Chronic meningococcus septicemia associated with pulmonary tuberculosis. Arch. of internal. Med. Vol. XVI. 1915. p. 487.

8. Chiari, Rückenmark von Meningitis suppurativa cerebrospinalis meningococcica. Deutsche med. Wochenschrift. 1915. S. 935.

9. S. Costa, Sur le diagnostic et le prognostic microbiologiques de la méningite cérébrospinale épidemique. $C . r$. Soc. $d$. Biol. T. LXXVI. 1914. p. 742.

10. H. Darré et J. Du mas, Nouvelle espèce de paraméningocoque. Pluralité des paraméningocoques. Eebenda. 1914. T. LXXVII. p. 106.

11. Chr. Dopter, Etude de quelques germes isolés du rhinopharynx voisins du méningocoque (Paraméningocoques). Ebenda. 1909. T. LXVI. p. 25.

12. Dopter et Pauron, La saturation des agglutines et des précipitines appliquée à la différentiation des méningocoques et des paraméningocoques. Ebenda. 1914. T. LXXVII. p. 157.

13. Diesclben, Différentiation des, paraméningocoques entre eux par la saturation des agglufines. Ebenda. p. 231.

14. Dieselben, La ,saturation des bactériolysines" appliquée à la différenciation du méningocoque et dés paraméningocoques. Ebenda. p. 292.

15. E. Duhot et L. Boez, Association de méningocoque et de colibacille au cours d'une méningite cérébrospinale. Ebenda. 1914. T. LXXVI. p. 795.

16. Heinrich Fischer, Beitrag zur Bakteriologie der Meningitis cerebrospinalis epidemica (Mischinfektion). Beiträge zur Klinik der Infekitionskrankheiten usw. 1916. Bd. V. S. 163.

17. Ernst Fränkel, Über dèn Nachweis von Meningokokken in der Lumbalflüssigkeit. Deutsche med. Wochenschrift. 1915. S. 1060.

18. Eug. Fränkel, Über petechiale Hauterkrankungen bei epidemischer Genickstarre. Beiträge z. pathologischen Anatomie usw, 1916. Bd. LXIII. S. 60. 
19. Fromme und Hanckon, Beurteilung von Umgebungsuntersuchungen und Meningokokkenträgern bei Bekämpfung der übertragbaren Genickstarre. Diese Zeitschrift. 1916. Bd. LXXXII. S. 243.

20. Gaethgens, Beitrag zur Bakteriologie der Meningitis. Zentralblall $f$. Bakt. usw. 1. Abt. Orig. 1914. Bd. LXXV. S. 41.

21. G. Gassner, Meningokokkenuntersuchungen anläßlich der Schweriner Genickstarreepidemie. 1917. Diese Zeitschrift. Bd. IXXXXIV. S. 279.

22. Derselbe, Hefewassernährböden und ihre Bewertung. Zentralblatt $f$. Bakt. usw. 1. Abt. Orig. Bd. LXXIX. 1917. S. 208.

23. Derselbe, Über das Mannitgärungsvermögen der Colibakterien. Ebenda 1917. Bd. LXXIX. S. 304.

24. Derselbe, Asparagin als Stickstoffquelle für Typhusbazillen. Ebenda. 1917.

25. A. Ghon, Meningitis Weichselbaum. Prager med. Wochenschrift. 1915. Bd. XL. S. 17.

26. Derselbe, Über die Einsendung von Untersuehungsmaterial zur Diagnose der Meningitis Weichselbaum. Ebenda. S. 187.

27. Ghon und B. Roman, Zur Klinik, Genese und Ätiologie der eitrigen Meningitis im Kriege. Med. Klinik. 1915. S. 1093.

28. F. Goebel und O. Hess, Beiträge zur Klinik der Therapie der epidemischen Genickstarre. Münchener med. Wochenschrift. 1915. S. 1655.

29. M. H. Gordon, Die wachstumshemmende Wirkung des Speichels auf Meningokokken. Brit. med. Journ. 1916. Nr. 2894 (zitiert nach Berlin. klin. Wochenschrift. 1916. 8. 927).

30. O. Götz und F. Hanfland, Zur Klinik und Therapie der Weichselbaumschen Meningokokkenmeningitis. Deutsche med. Wochenschrift. 1916. S. 1284.

31. C. Gram, Über die isolierte Färbung der Schizomyceten in Schnitt- und Trockenpräparaten. Fortschr. d. Medizin. 1884. Bd. II. S. 185.

32. G. B. Gruber, Zur Lehre von Wesen, Verbreitung und Bekämpfung der Meningokokkenmeningitis. Diese Zeitschrift. 1915. Bd. LXXX. S. 219.

33. Derselbe, Über das Exanthem im Verlaufe der Meningokokkenmeningitis (,Genickstarre“). Deutsches Archiv t. klin. Medizin. 1915. Bd. CXVII. S. 250.

34. Derselbe, Über das Exanthem im Verlaufe der Meningokokkenmeningitis. Münchener med. Wochenschrift. 1915. S. 786.

35. W. Hancken, Zur Bakteriologie der Meningokokken. Zentralblatt f. Balt. 1. Abt. Orig. 1916. Bd. LXXVIII. S. 365 .

36. A. Harzer und K. Lange, Beitrag zur Frage der Differentialdiagnose von Meningokokken. Münchener med. Wochenschrift. 1916. S. 950. S. 1087.

37. G. Herzog, Zur Diagnose der epidemisehen Genickstarre. Ebenda. 1915.

38. Herzog, Sanitätsrat, Akuter Gelenkrheumatismus und Meningitis. Deutsche med. Wochenschrift. 1916. S. 1352.

39. H. Hochhaus, Über die abortiven Formen der Meningitis cerebrospinalis. Ebenda. 1915. S. 1185.

40. E. C. Hort, Die Bedeutung der Meningokokken für die Ätiologie der Genickstarre. Brit. med. Journ. 1916. (Zitiert nach Berlin. klin., Wochenschrift. 1916. S. 286).

41. Th. Hryntschak, Ein Fall von Meningitis cerebrospinalis siderans. Wiener klin. Wochenschrift. 1915. S. 1566. 
42. A. Jaiser, zitiert nach Fischer (16).

43. R. Imhofer, Meningokokkenwundinfektion nach Halsdurchschuß. Med. Klinik. 1917. S. 270.

44. K. Isaak, Die Behandlung der Meningokokkenträger mit Eucupin. Münchener med. Wochenschrift. 1917. S. 1009.

45. Jochmann, Übertragbare Genickstarre als Kriegsseuche. Zeitschrift für äratliche Fortbildung. 1914. S. 759.

46. L. Justitz, Eine neue und wirksame Methode zur Entkeimung von Meningokokkentrügern. Münchener med. Wochenschrift. 1916. S. 1283.

47. R. Klinger und F. Fourman, Zur Bakteriologie und Prophylaxe der Meningitis epidemica. Ebenda. 1915. S. 1037.

48. Köhlisch, Bakteriologische Befunde bei einem Fall von Meningokokkensepsis; gibt es eine Mutation bei Meningokokken? Diese Zeitschrift. 1915. Bd. LXXX. S. 404 .

49. J. Kudruáč, Zur Therapie der Genickstarre. Therapie der Gegenwart. 1917. S. 211.

50. Marie Kurák, Die Behandlung der Meningitis cerebrospinalis mit großen Serummengen. Medizinische Klinik. 1915. S. 1054.

51. E. Küster, Behandlung der Meningokokken- und Diphtheriebazillenträger. Deutsche med. Wochenschrift. 1915. S. 1116.

52. E. Küster und H. Günzler, Zur Behandlung von Meningokokken- und Diphtheriebazillenträgern. Zentralbl. f. Bakteriol. Abt. I. Orig. 1916. Bd. LXXVIII. S. 442.

53. R. v: Kutschera, Genickstarre im Pustertal. Wiener klin. Wochenschrift. 1915. S. 470 .

54. v. Lingelsheim, Über einen neuen Infektionserreger bei epidemischer Influenza. Münchener med. Wochenschrift. 1917. S. 606.

55. I. Lloyd, Beachtenswerte Winke für die Bereitung von Blutagar für Meningokokken. Brit.Med.Journ. 1916. No. 2900 (Zitiert nach Berl. klin. Wachenschrift. 1916. S. 1059).

56. E. Mangelsdorf, Übertragbare Genickstarre. Deutsche Militäräratliche Zeitschrift. 1916. Nr. 22-24.

57. H. Morgenstern, Exanthem und Rezidiv bei Meningitis epidemica. Deutsche med. Wochenschrift. 1915. S. 1263.

58. H. Mühsam, Beiträge zur Pathologie und Therapie der Hirnhautentzündung, insbesondere der epidemischen Genickstarre. Wiener klin. Wochenschrift. 1916. S: 1293 .

59. N. Obé, Ein einfaches Verfahren zur Erleichterung des Nachweises von Meningokokken in der Lumbalflüssigkeit. Münchener med.Wochenschrift, 1915. S. 610.

60. A. Orticoni, Le pronostic cylotogique et bactériologique de la méningite cérébrospinale. C. r. Soc. d. Biol. 1914. T. LXXVI. S. 602.

61. Petruschky, Zur Vorbeugung der epidemischen Genickstarre. Münchener med. Wochenschrift. 1915. \$. 1306, 1667.

62. I. Pick, Histologische und histologisch-bakteriologische Befunde beim petechialen Exanthem der, epidemischen Genickstarre. Deutsche med. Wochenschrift. 1916. S. 994.

63. S. Pollag, Parameningokokkenmeningitis. Münchener med. Wochensehrift. 1917. S. 771 . 


\section{Johannes Zeissier und Gustay Gassner: Die Diagnose usw.}

64. Nathan Rosenbaum, Ein unter eigentümlichen Symptomen auftretender Fall von Meningitis cerebrospinalis epidemica fulminans. Medizinische Klinik. 1915. S. 1424 .

65. V. K. Russ, Die Bedeutung der Meningokokkenträger für das Militär. Militärmed. und ärztl. Kriegswissenschaft. Wien und Leipzig. 1914. S. 201.

66. E. Sacquépée et Delater, Nouveau milieu de culture pour le méningocoque et des germes voisins. C. r. Soc. d. Biol. 1914. T. LXXVII. S. 224.

67. R. Scheller, Influenza oder Grippe? Deutsche med. Wochenschrift. 1917. S. 1005 .

68. Schlesinger, Demonstration einer Frau mit Meningitis levissima (epidemica). Berlin. klin. Wochenschrift. 1915. S. 1294.

69. H. Schottmüller, Über Meningitis cerebrospinalis epidemica (Weichselba u msche Meningitis). Münchener med. Wochenschrift. 1905. S. 1617, 1683, 1729.

70. J. Schwenke, Über Meningitis cerebrospinalis epidemica mit hämorrhagischen Hautausschlägen. Deutsche med. Wochenschrift. 1916. S. 318.

71. H. Silbergleit und K. v. Angerer, Klinische und bakteriologische Beobachtungen bei Meningitis epidemica (Mischinfektion bei Meningitis epidemica). Deutsche Med. Wochenschrift. 1916. S. 7.

72. A. Spitzer, Über ansteckende Krankheiten der Kriegszeit. Liječnički Vijesnik. 1915. Vol. XXXVII. S. 71. (Zitiert nach Zentralblatt f. Bakt. Ref. 1916. Bd. LXIV. S. 572).

73. Staehelin, Über epidemische Genickstarre. Berliner klin. Wochenschrift. 1915. S. 621 .

74. R. Stephan, Über eine unter dem Bilde des Meningismus verlaufende Allgemeininfektion mit gramnegativen Diplokokken. Münchener med. Wochenschrift. 1916. S. 670.

75. R. Stephan, Über einen neuen Infektionserreger bei epidemischer In. fluenza. Münchener med. Wochenschrift. 1917. S. 257.

76. V. Svestka, Meningokokkensepsis. Wiener klin. Wochenschrift. 1915. S. 1319.

77. v. Tabora, Bericht über den Stand der jetzigen Mcningitis cerebrospinalis-Epidemie. Deutsche med. Wochenschrift. 1915. S. 995.

78. "Times". Die Bekämpfung einer ansteckenden Krankheit in der Armee. Von dem ärztlichen Mitarbeiter. Times vom 15. 1. 1917.

79. F. Umber, Flecktyphusartiger Verlauf von Genickstarre. Medizinische Klinik. 1915. S. 187.

80. S. Vomela, Meningitis Weichselbaum. Lékařské Rozhledy. Bd. XXII. S. 396.

81. K. Walko, Weiterer Beitrag zu den Mischinfektionen mit epidemischen Krankheiten im Kriege. Prager med. Wochenschrift. 1915. Bd. XL. S. 215.

82. G. Wolff, Der Vetsuch einer neuen Meningitisbehandlung mit Silberpräparaten. Deutsche med. Wochenschritt. 1915. S. 1486.

83. M. Wollstein, Parameningicoccus and its antiserum. Journ of experim. Med. 1914. Vol. XX. S. 20.

84. Joh. Zeissler und F. Riedel, Zwei Fälle von Meningokokkensepsis ohne Meningitis und ihre Diagnose. Deutsche med. Wochenschrift. 1917. S. 258.

85. Joh. Zeissler, Zur Züchtung des Bacillus phlegmonis emphysematosae Eug. Fraenkel. Deutsche med. Wochenschrift. 1917. S. 878. 